\title{
O ARGUMENTO DE PUTNAM CONTRA O SENHOR SKEP: POR QUE KANT ESTAVA CERTO QUANTO À EXISTÊNCIA DO MUNDO EXTERIOR?
}

Luis Milman, $\mathrm{PhD}$ *

SÍNTESE - O artigo defende a validade dos argumentos transcendentais. Hilary Putnam fez uso deste tipo de argumento para fixar uma condição metafísica para a semântica. Seu raciocínio segue o estilo de inferência desenvolvido por Kant, na refutação do ceticismo fenomenista e idealista. Segue-se da argumentação de Putnam a necessidade metafísica do princípio externalista em semântica. Com isso, desarmam-se as tentativas de fixar condicionamentos exclusivamente intersimbólicos para a constituição do significado.

PAIAAVRAS-CHAVE - Argumentos transcendentais. Propriedades semânticas. Externalismo. Internalismo. Ceticismo. Necessidade metafísica. "Cérebros em uma pipa". O meio excluido.
ABSTRACT - The essay is about the validity of transcendental arguments. Hilary Putnam used a variation of these arguments to obtain a metaphisical semantic condition. Putnam's reasoning is classical, in kantian sense. From that inference follows what I call "the externalist semantic principle" and, a fortiori, a strong reason to reject purely internalist views in semantics.

KEY WORDS - Transcendental arguments. Semantic proprieties. Externalism. Internalism. Skepticism. Metaphisical nececessity. Brains in a vat. The excluded middle

\section{Introdução}

Os filósofos realistas tradicionalmente discutem o ceticismo. Aristóteles discutiu Pirro, Kant discutiu Descartes e Hume, Popper discutiu Kuhn. E a razão é simples: os céticos, de há muito, têm levantado dúvidas sérias sobre a natureza da verdade, do conhecimento e da experiência. Mais recentemente, pontos de vista distintos sobre a relação entre nossos pensamentos e os objetos dos nossos pensamentos recolocam certas teses céticas no centro das discussões filosóficas sobre a possibilidade de explicar a psicologia (incluindo aí a descrição completa de esta-

* Universidade Federal do Rio Grande do Sul. Endereço: Rua Francisco Ferrer, 504/91 - Porto Alegre/RS-Brasil - CEP: 90420-140 - Fone: 51-332-2141 - E-mail: milman@voyager.com.br 
dos e processos mentais) por meio de teorias funcionalistas. Alguns teóricos acreditam que descrições funcionais são, conceitual e empiricamente, suficientes para dar conta de nossos processos mentais. Crenças, desejos e outros estados mentais podem ser descritos como estados funcionais internos do cérebro (ou de mecanismos artificiais capazes de cognição). A relação entre tais estados e coisas exteriores ficaria refutada, no caso de haver alguma prova capaz de provar que a noção semântica de "conteúdo de um símbolo" é funcional. Ou seja, que ela não depende de relações que símbolos mantêm com coisas no mundo, mas de relações que símbolos mantêm entre si.

Neste contexto, Hilary Putnam, que defendia o funcionalismo nas décadas de $60 / 70$, propôs, contra suas posições iniciais, um argumento que refuta a possibilidade da semântica funcionalista. Seu argumento tomou-se clássico, não apenas pelo contraponto que faz à hipótese da semântica funcional. Ele também adverte para a complexidade do tema das propriedades semânticas. O funcionalista, como o cético, acredita que a conexão entre a propriedade de ser um símbolo e a propriedade de fazer referência a algo fora do pensamento não é necessánia. Kant afirmava que crenças deste tipo não podem ser fundamentadas racionalmente. Ele abriu o caminho e Putnam faz um uso refinado do raciocínio kantiano para bloquear as crenças puramente internalistas em Semântica. Neste artigo, pretendo analisar os pontos que fazem do argumento de Putnam um argumento racionalmente irrecusável.

\section{Kant e o anticeticismo local}

A idéia segundo a qual há compromissos que assumimos a priori quando pensamos na experiência possível, é a idéia de Kant acerca da verdade, independentemente da experiência de alguns enunciados ou juizos sintéticos. Kant disse que certos juízos são sintéticos e a priori, devido a uma propriedade especial: eles nos informam sobre as precondições gerais da experiência. ${ }^{2}$ Ele, evidentemente, sabia que nenhum juizo informativo pode ser reconhecido como verdadeiro a priori, se nos

\footnotetext{
O estatuto destes compromissos é, para Kant, estritamente conceitual, e este traço distinguia a sua natureza apriorística da natureza empírica dos demais juízos sintéticos, que podem ser verdadeiros ou falsos em virtude do que afirmam a posteriori dos objetos da experiência. Não é nesse sentido puro que desejo promover a discussão sobre a possibilidade do raciocínio a priori. Trata-se, como ficará claro na explanação do argumento transcendental - e do argumento de Putnam - de explicitar os passos de um raciocínio que se legitima não porque fixa compromissos com postulados de natureza puramente conceitual, mas porque examina a impossibilidade de refutar os postulados sobre as condições gerais do conhecimento e da expenência tendo-se por base a aceitação de hipóteses gerais e a posteriori sobre como obtemos experiência e conhecimento das coisas. Não se trata de afirmar que os postulados que os céticos fracassam em refutar se imponham porque pertencem a uma ordem conceitual pura (como Kant os entendia). Para o que é decisivo demonstrar aqui, importa discutir se é possivel ou não refutá-los com base no que aceitamos a posteriori.

A explicação da possibilidade de juízos sintéticos é uma tarefa que a lógica geral não tem de se ocupar, nem sequer tem mesmo a necessidade de conhecer o nome. É, porém, o mais importante de todos os assuntos de uma lógica transcendental, e até o único, quando se trata da possibilidade de juízos sintéticos a prion, bem como das suas condições e da extensão da sua validade[...]." Cf. I. Kant, “Analítica dos Princípios", II-2 $2^{\underline{a}}$ seção, B 194. In: Kritik der Reinen Vemunft, $2^{\mathrm{a}}$ ed., 1787, trad. port. Crítica da Razão Pura, Lisboa, Fundação Calouste Gulbekian, 1989.
} 
informa sobre propriedades que os objetos da experiência possuem. O seu problema, portanto, era definir sobre o que os juízos sintéticos a prion nos informam, se não são juizos relacionados às propriedades das coisas.

Para Kant, os juízos a priori sintéticos concernem aos princípios da unidade da sintese dos fenômenos empíricos. O seu projeto era fundamentar racionalmente a aceitação de tais principios, que dizia concementes às condições necessárias do "conhecimento da experiência possivel em geral".

Um alerta: podemos aceitar que há juízos sintéticos a priori e rejeitar a doutrina kantiana da consciência transcendental. ${ }^{4}$ A vinculação entre o argumento transcendental e a doutrina do sujeito transcendental não é necessária, como o próprio Kant demonstra, na Crítica da Razão Pura. Como o compromisso com a doutrina transcendental da consciência pode viciar a compreensão do argumento analítico que Kant formula, nada mais compreensivel do que a opinião de Strawson, por exemplo, sobre o principal mérito e o principal equívoco de Kant no que concerne ao estatuto deste argumento. Strawson recomenda separar "a doutrina transcendental, segundo a qual a fonte de todas as características limitadoras e necessánias da experiência se encontram em nossa constituição cognitiva, que é incoerente em si mesma e que antes de explicar, mascara o caráter real desta explicação, do argumento analítico que é de fato independente dela". 5

O argumento que Strawson chama de analítico é o mesmo que nós chamamos de transcendental, embora Kant não tenha se referido a ele com esse nome. ${ }^{6}$ A sua força está na possibilidade de ser usado para fixar proposições sintéticas a prioni. Essa constatação torna-se evidente quando analisamos a $2^{\mathrm{a}}$ Analogia da Experiência e a Refutação do Idealismo, ${ }^{8}$ onde Kant demonstra que o ceticismo é racionalmente inaceitável. A prova expõe a incoerência entre as teses céticas e determinados pressupostos tacitamente aceitos pelos céticos, na formulação das suas próprias teses. Esquematicamente:

\section{Op. cit. B 197}

Kant formulou a doutrina transcendental da consciência, sobretudo, na sua Lógica Transcendental (Crítica, "Analítica dos Conceitos", $2^{\mathrm{a}}$ parte, $1^{\mathrm{a}}$ divisão, livro I, cap. II, seção I, \& 13-27. Peter Strwason,The Bounds of Sense, An Essay on Kant's Critique of Pure Reason, London, Methuen \& Co. Ltd, 1966, 5ㄹ. ed. London-New York, Routledge, 1993,. p.15-6 Strawson afirma que somente um argumento deste tipo, que é independente da psicologia transcendental kantiana, pode garantir a adoção da sua Tese da Objetividade da Experiência (The Bounds of Sense, Parte Dois, Seção Dois, \& 5-7). "Vamos considerar, independentemente das doutrinas da psicologia transcendental, a tese de que para uma série de diversas experiências pertencerem a uma consciência única, é necessário que elas sejam de tal modo conectadas que constituam uma experiência temporalmente estendida de um mundo objetivo unificado". Peter Strawson, op. cit. p. 97. E ainda: "A unidade das diversas experiências numa consciência singular requer a experiência de objetos. Podemos testar a força desta tese observando como ela resiste a ataques" ibid. p. 98.

7 P. Strawson, Op. cit, pp.15-16. Por essa razão, ele conclui que "Kant realmente não tem uma idéia geral e clara do sintético a priori". Op. cit. p. 43.

8 No caso da " $2^{\text {a }}$ Analogia", está em jogo a refutação do ceticismo empirista humeano, segundo o qual não há procedimento racional válido capaz de nos impor a aceitação de um princípio geral de causalidade; no caso da "Refutação", está em jogo (principalmente) o que Kant chamou de "idealismo problemático", i.é., o ceticismo cartesiano relativo à cognoscibilidade do mundo externo. Cf. Crítica, "Segunda Analogia da Experiência", $2^{a}$ Parte, I, Livro Segundo, seção 3, \& B 233- B 256; "Refutação do Idealismo", \& B 275- 287. 
i) as teses céticas sobre o que é razoável aceitar, dentro dos limites do nosso conhecimento e da nossa experiência, contêm pressupostos acerca do tipo de conhecimento/experiência possiveis;

ii) o cético não poderia formular sua tese se não aceitasse, ainda que tacitamente, tais pressupostos;

iii) o cético acerta quando afirma que os pressupostos não podem ser extraídos da experiência (v.g., o princípio da causalidade); mas enra quando não os reconhece como passíveis de justificação racional. Os pressupostos são condições de possibilidade a priori da experiência;

iv) as teses céticas refutam a si próprias, na medida em que supõem tacitamente as proposições que pretendem negar.

Nestas seções da Crítica, o raciocínio de Kant é indireto: para demonstrar que a posição cética é insustentável, Kant denuncia a incompatibilidade conceitual entre (a) o que os céticos concluem sobre a experiência e o conhecimento e (b) o que eles supõem para chegar a essas conclusões. Em outras palavras, Kant mostra que (a) as noções de experiência sensorial e de conhecimento ideacional ou interno (que são as premissas aceitas pelos céticos), não são conciliáveis conceitualmente com (b) a afirmação de que todo o conhecimento é empírico ou de que não podemos inferir do conhecimento da representação das coisas a existência de um mundo externo.

O argumento é uma reductio ad absurdum: proposições sobre a experiência e o conhecimento, que os céticos julgam poder demonstrar contradizem certas suposições gerais, feitas pelos próprios céticos, acerca do que torna possível a experiência e o conhecimento. Somos convencidos indiretamente da necessidade de certos princípios que determinam a experiência, ao examinar os próprios argumentos que pretendem demonstrar que estes princípios não podem ser aceitos porque não se justificam empiricamente.

Entretanto, este convencimento só pode, estritamente, refutar o cético. Ele é incapaz de produzir qualquer evidência sobre as condições efetivas do conhecimento. ${ }^{9}$ Kant faz uma distinção importante no que se refere a dois métodos distintos de demonstração: por um lado, ele afirma que não se pode derivar a prova da consciência transcendental por meios não-ostensivos ou indiretamente, ao dizer que não se pode conhecer a origem das regras a priori da experiência por meio da refutação de argumentos que negam a existência de tais princípios. Mas, por outro lado, pode-se produzir indiretamente uma prova da indispensabilidade de tais principios, pois sem eles não poderíamos pensar em experiência alguma.

\footnotetext{
Na "Doutrina Transcendental do Método" (Parte II, Cap. I, Seção 4), Kant descarta o uso de demonstrações apagógicas para propósitos transcendentais" [...] A demonstração direta ou ostensiva é, em toda a espécie de conhecimento, aquela que junta à convicção da verdade à visão das fontes dessa verdade; a demonstração apagógica, pelo contrário, pode sem dúvida produzir a certeza, mas não a compreensão da verdade considerada na sua relação com os principios da sua possibilidade. Por isso, as demonstrações desta segunda espécie são mais um recurso, em caso de necessidade, do ponto de vista da evidênciça a todos os desígnios da razão. Contudo possuem uma vantagem, consigo mais clareza na reprea, sobre as provas diretas, a saber, que a contradição traz sempre ráter intuitivo de uma demonstração.") Op cit. B 818 .
} 
Uma das principais objeções dirigida contra o esquema inferencial proposto por Kant é aquela segundo a qual as conclusões que o esquema estabelece não são universais, porque não são capazes de refutar todas as concepções alternativas sobre a experiência e o conhecimento que os céticos podem, em princípio, formular coerentemente. Esta acusação desqualifica a alegada pretensão à universalidade do argumento kantiano. A formulação clássica desta objeção foi feita por Stephan Körner:

A pessoa que propõe um argumento transcendental assume que todos os que pensam, empregam a mesma armação conceitual que ela emprega, e tenta mostrar que, e por que, o emprego desta armação particular é 'necessário'. O defeito de todos os argumentos transcendentais é o fracasso (destes argumentos) em obter uma única prova, isto é, uma demonstração da unicidade desta armação conceitual. ${ }^{10}$

Richard Rorty segue os passos de Körner. Ao afirmar que os argumentos transcendentais refutam apenas formulações específicas e localizadas do ceticismo, ele conclui que tais argumentos não possuem nem o alcance nem a necessidade que Kant imaginava que possuíam:

[...] (o argumento transcendental) apenas reconhece que uma alternativa sugerida ao nosso presente entendimento não funciona. Tudo o que os argumentos paradigmáticos de Kant fazem é mostrar que uma dada descrição alternativa cética da experiência ou do conhecimento apenas parece fazer sentido porque, nos termos de Strawson, 'o cético parece aceitar um esquema conceitual, mas ao mesmo tempo rejeita uma das condições para o seu emprego'. Mostrar que todas as alternativas propostas teriam a mesma falha seria o mesmo que conhecer antecipadamente a extensão da imaginação cética. Saber antecipadamente que qualquer descrição alternativa do conteúdo ao qual esperamos que nosso esquema corresponda (ou, no que dá no mesmo, qualquer esquema conceitual aiternativo) teria este defeito e corresponderia a ser capaz de fazer em filosofia aquilo que ninguém sonha poder fazer em ciência -predizer que qualquer nova teoria que surgirá será meramente uma versão distinta da nossa teoria. Sem 'princípios metafisicamente dogmáticos', não podemos fazer em filosofia aquilo que não podemos fazer fora dela, sendo a filosofia auto-referente ou não. Todos os argumentos auto-referenciais são argumentos ad hominem - e mostram que essa proposta tacitamente pressupõe aquilo que ela pretende negar. Não pode haver tal coisa como argumentos auto-referenciais indiscriminados para conclusões negativas. ${ }^{11}$

Seria impossivel, segundo essa crítica, garantir que hipóteses ainda não formuladas venham a confirmar as características de um determinado esquema ou arquitetura conceitual invariante. ${ }^{12}$ Rorty parece atribuir a Kant e a seus seguido-

10 Stephen Kömer, Categorial Frameworks, Oxford, Blackwell, 1974, p.72

11 Richard Rorty, "Transcendental Arguments, self-reference and pragmatism", In: Transcedental Arguments and Science, R. P. Bieri et alii (eds), Dordrecht, Riedel Publishing Co., 1979, p. 82.

12 Richard Rorty, op. cit. p. 82. Ao apresentar os argumentos transcendentais como auto-referenciais, Rorty está usando a caracterização de Rüdiger Bubner, segundo a qual "o argumento de tipo transcendental avança decisivamente sobre a demonstração meramente fatual. Este avanço depende do momento lógico da auto-referencialidade. Se fica aparente que mesmo o raciocínio sobre as formas fatuais de conhecimento e de clarificação de suas precondições não é possivel sem que se faça uso de certos elementos, então não é meramente um estado đe coisas fatual que está sendo demons- 
res, uma abordagem filosoficamente ingênua dos problemas epistemológicos, pois os acusa de confundir (a) o que deveria ser apresentado como mera evidência de uma possivel falta de imaginação dos céticos, com (b) uma prova de impossibilidade a priori ou conceitual.

Rorty e Kömer estão erradọs. Eles perceberam que os argumentos kantinanos são localizados (ad hominem, como Rorty prefere). Mas não perceberam que é esta a característica que os toma racionalmente irrepreensiveis. Rorty e Kömer erram ao supor que Kant desejava refutar o ceticismo indiscriminadamente. Tanto na Refutação do Idealismo como na $2^{\text {a }}$ Analogia, os argumentos transcendentais estabelecem suas conclusões justamente porque levam em conta hipóteses céticas específicas acerca da experiência de objetos e da origem da noção de causalidade.

Os argumentos kantianos fixam condições gerais de possibilidade da experiência e do conhecimento que o cético descreve. Suas conclusões nos chamam a atenção para a incoerência de argumentos céticos específicos, que pretendem nos convencer da impossibilidade de justificação de certos princípios para os quais não podemos recorrer a uma fundamentação empírica ou lógica. Quando falamos em argumentos céticos específicos, estamos nos referindo às teses que possuem premissas definidas. No caso do ceticismo acerca do tatus racional do princípio da causalidade, a premissa que Hume aceita é a de que temos experiência da sucessão de eventos no tempo. E no caso do ceticismo cartesiano, a de que temos experiência de estados internos da mente. E o que singulariza os argumentos kantianos é o fato de que, ao explicitar os pressupostos que são conceitualmente necessários para a descrição das experiências que estes céticos aceitam, ele torna explícitas as condições de possibilidade para que as próprias teses céticas possam ser formuladas.

Ao demonstrar que as conseqüências implicadas pela aceitação destes pressupostos contradizem aquilo que os argumentos céticos específicos pretendiam provar, Kant refuta essas alternativas. Ou ainda, como sustenta Förster, na medida em que procede estritamente desta maneira, Kant exaure o campo de explicações alternativas possiveis às condições de possibilidade que os seus argumentos
transcendentais impõem. ${ }^{13}$

Os argumentos transcendentais kantianos e pós-kantianos são tópicos e funcionam dentro dos limites estabelecidos pelos argumentos céticos que eles atacam. Mas não se trata de afirmar que, ao refutar certas modalidades de ceticismo, Kant exaure o campo de concepções que possam vir a ser propostas como altemativas céticas inéditas. Em caso de altemativas céticas novas, elas não seriam altemativas para os argumentos de Kant, mas sim de altemativas às próprias altemativas céticas que Kant

trado. Mais do que isso, é uma estrutura lógica que mostra a validade desta forma de conhecimento. Não apenas ocorre que não há altemativas a esta forma; ninguém pode, em principio, conceber blem of Deduction", In: Review of Metaphysics, 28, 1928 Transcendental Arguments and the ProEckart Förster, "How Are Transcendental Arguments Possible, p.14. 
desautorizou. Diante de possiveis novas altemativas, poderemos proceder da mesma forma que Kant procederia; ou seja: examinaremos se as precondições da experiência ou do conhecimento admitidas pelo (novo) cético, acarretam ou não a impossibilidade do (novo) ceticismo. ${ }^{14}$ Este é caso da Hipótese dos Cérebros numa Cuba.

\section{Putnam e o senhor Skep}

As observações sobre Kant localizam o raciocínio de Hilary Putnam numa linha clássica de argumentação. Seu alvo específico, no entanto, é o ceticismo acerca de uma semântica denotacional ou externalista, que se expressa afirmativamente em teorias funcionais do significado. Putnam pretende demonstrar que, do ponto de vista semântico, é indispensável reconhecer a validade do princípio segundo o qual certos termos e/ou sentenças de nossa(s) linguagens(s) ordinánia(s) estão necessariamente conectados a objetos ou a estados de coisas extemos, por algum tipo de relação que estes termos mantêm com estes objetos.

Se Putnam estiver correto, a condição metafísica externalista para a semântica é impositiva e referir-se a é uma propriedade não intrínseca de uma determinada linguagem. Símbolos são o que são em virtude de relações que mantêm com denotata que estão fora de nós, como diria Descartes. Logo, não pode haver conexão exclusivamente interna entre (a propriedade de) ser um símbolo e (a propriedade de) pertencer a uma linguagem.

Putnam apresenta as características do seu argumento da seguinte forma:

Nossa tarefa constituiu-se em examinar as precondições do pensamento acerca de algo, [...]. E as investigamos [...] raciocinando a prioni. E não no antigo sentido "absoluto" (já que não pretendemos que as teorias mágicas da referência sejam errôneas a priori), mas no sentido de uma investigação sobre o que é racionalmente possivel uma vez assumidas certas premissas gerais, ou uma vez estabelecidas suposições teóricas muito gerais. Tal procedimento não é empírico, mas tampouco é completamente a priori, ainda que incorpore elementos de ambas as formas de investigação. Apesar de ser falível e depender de supostos que poderiam ser descritos como empíricos (por exemplo, o suposto de que a mente não tem outro acesso às coisas externas ou às propriedades externas, a não ser aquele que the proporciona os sentidos), meu procedimento se encontra em estreita relação com o que Kant chamou de "investigação transcendental", já que consiste em uma investigação sobre as precondições da referência e, conseqüentemente, do pensamento - precondições que se encontram incorporadas na natureza de nossas mentes, ainda que não sejam (como acreditava Kant) completamente independentes de suposições empiricas. ${ }^{15}$

14 A objeção de Korner-Rorty ignora a diferença entre dois tipos de ceticismo, o local e o anáquico. Graham Bird define como local o ceticismo que atribui determinadas características à experiência. $\mathrm{Na}$ " $2^{\mathrm{a}}$ Analogia" e na "Refutação do Idealismo", Kant queria desarmar essa modalidade de criticismo Mas há outra categoria cética, de contornos mais amplos e que desafia a possibilidade da experiência e do conhecimento in totum. Nele, o cético nega que tenhamos experiências externas e internas, por exemplo. Concordo com Bird, na sua afirmação de que este tipo de ceticismo "anárquico" não preocupava a Kant. Para uma visão mais detalhada da plausibilidade de um anarcoceticismo, cf. Graham Bird, "Kant's Transcendental Arguments"; In: E. Chaper e W. Vossenkhul (orgs.) Reading Kant, pp. 26-7.

H. Putnam, Razon, Verdad e Historia, pp.28-9. 
$\mathrm{O}$ argumento pretende denunciar a incoerência de uma variação do ceticismo cartesiano sobre possibilidade de conhecermos algo por meio dos sentidos. A hipótese cartesiana tradicional, exposta na Primeira Meditação ${ }^{16}$ diz respeito à incognoscibilidade do mundo exterior, não à sua irrealidade. Isto é ilustrativo, porque há formas de ceticismo que não se comprometem com a verdade desta tese. Se prestarmos atenção no cético cartesiano, por exemplo, ele estritamente não dirá que não há mundo exterior. O que estritamente ele dirá é que não podemos ter certeza de nada sobre o mundo exterior, dado o tipo de experiência que temos. Logo, ele pode ser realista e sustentar que a verdade não é objeto de conhecimento, que a existência de algo fora de nós não pode ser provada por qualquer dispositivo cognitivo disponível para nós. Chamemos a esta posição de ceticismo epistêmico radical. Ele é distinto do ceticismo anti-realista radical, que questiona, a partir da incognoscibilidade do mundo externo, a própria realidade do que é exterior a nós. Note-se, no entanto, que a refutação de Putnam, se cogente, aplica-se a ambos, porque tanto o cético realista como o idealista pretendem ser racionais na sua descrença e afirmam que não podemos conhecer nada que nos seja exterior. Este é o ponto importante, porque é o pressuposto geral implicado pela hipótese da incognoscibilidade, a saber, que a mente somente possui acesso aos seus próprios conteúdos.

O que acontece se não pudermos refutar esta hipótese? Não há como sustentar que o mundo exterior pode ser conhecido; e que tampouco a referência de nossas palavras pode ser conhecida. Na medida em que não nos é possível afirmar com certeza que nossas palavras se referem a coisas exteriores, somos forçados a aceitar que elas se referem somente a representações (imagens, idéias, conceitos, etc...), e não às coisas mesmas. Segue-se, plausivelmente, da falta de uma prova conclusiva da realidade do mundo exterior, que a referência dos nossos termos não é externa.

Imaginemos uma pessoa que é cética com relação a tudo o que é exterior a nós (o senhor Skep, digamos). Skep acredita que o enunciado $E$ "somos cérebros numa cuba" pode ser de fato verdadeiro. Logo, Skep acredita que a verdade, ao menos com relação a algumas proposições, é uma noção aplicável. Por exemplo, a hipótese, viz. que não há distinção entre nossas experiências e as experiências de um CNC, que não há nada que possamos dizer ou fazer que não possa ser feito por um CNC, é uma hipótese que ele crê ser verdadeira. Ele justifica o que diz com o desafio de Descartes: como só podemos ter certeza daquilo que temos experiência e como só temos experiências de sensações e pensamentos, nada nos impede que sejamos CNC. O senhor Skep fundamenta a crença na possível verdade de $E$ em dois pontos: (a) estritamente, não há quaisquer evidências capazes de provar empiricamente que $E$ seja falso; (b) $E$ é um caso particular de uma premissa geral que nega que tenhamos acesso (imediato ou mediato) às coisas fora de nós.

${ }^{16}$ Cf. Renné Descartes, Meditações de Filosofia Primeira, Primeira Meditação (o Argumento do Sonho e a Hipótese do Gênio Maligno) \& 1-12. 
Para um realista, o problema é que a hipótese do senhor Skep parece não apresentar nenhum vício de racionalidade (ela não é refutada pela evidência e não contradiz as premissas das quais é derivada). Como Kant, no entanto, Putnam vai forçar o hipotético sr. Skep - que diz poder ser um CNC - a enfrentar um paradoxo transcendental: condicionamentos que o sr. Skep necessária e implicitamente aceita quando formula a sua hipótese são incompatíveis com aquilo que a hipótese explicitamente afirma ser verdadeiro. Ou seja, Putnam vai mostrar que é logicamente impossivel que alguém como o senhor Skep seja um CNC, porque o enunciado "somos CNC" contraria pressupostos lógicos inerentes ao argumento que (supostamente) deveria sustentá-lo.

A batalha de Putnam contra o hipotético sr. Skep é travada num cenário contemporâneo, porque o problema da semântica funcional é um problema contemporâneo, e se expressa na possibilidade de construirmos máquinas que tenham uma psicologia idêntica à nossa. No lugar do sonhador cartesiano, há um CNC, cuja vida mental é inteiramente dependente de um supercomputador (Super C). Super $\mathrm{C}$ fornece ao $\mathrm{CNC}$ todas as informações sensoriais que o fazem pensar que ele não é um $\mathrm{CNC}{ }^{17}$

O sr. Skep afirma que seres como nós somos, podem ser $C N C$. Neste mundo possivel, as experiências de um $C N C$ são alucinações, porque os CNC, pelo menos inicialmente, não sabem que são CNC. Não fossem pessoas como Skep, eles permaneceriam seguros de que são pessoas como nós e jamais pensariam seriamente que podem ser cérebros numa cuba.

Mesmo quando imaginam que podem ser CNC, os CNC acreditam (erroneamente) que não estão numa cuba tendo experiências sensoriais implantadas. Eles acreditam (equivocadamente) que sabem quais são os limites entre a realidade e a ficção. Para eles, reais são as experiências de coisas que eles pensam pertencer ao mundo externo, a um mundo que não existe em suas mentes, mas fora delas. Quando um CNC experimenta, por exemplo, que está proferindo uma palestra sobre fisica quântica, ela emite um comando às suas terminações eferentes, que é conduzido ao supercomputador. Este, por sua vez, envia um estímulo-resposta do tipo "estou fazendo uma palestra sobre fisica quântica", que dá ao CNC a impressão de estar realmente palestrando e o leva a acreditar que realmente está palestrando para pessoas de carne e osso sobre um tema científico.

17 Holliwood, aliás, já "descobriu" Putnam e produziu um filme no qual há corpos com cérebros, e estes corpos com cérebro vivem entubados em esquifes controlados por uma perversa maquinaria robótica. Ao descobrirem que não são o que pensam que são, alguns deles libertam-se e passam a combater o vilão-máquina. A versão é adaptada ao gosto adolescente por ficçōes cibernéticas. No filme há um mundo extemo que é o mundo real (com corpos-com-cérebros-reais, atomosfera real, um Super-C e máquinas reais, etc.) e um mundo ilusório (o mundo gerenciado pelo Super-C, onde tudo é falso) Os heróis, ao descobrirem que são reais e que viviam ilusões enquanto dormiam, fogem para a realidade, pegam em armas e salvam o mundo. Na história de Putnam, se um CNC descobrisse que é de fato um $\mathrm{CNC}$, além de ser difícil que saltasse para fora da cuba, para onde ele estaria saltando? O filme não faz jus ao argumento de Putnam. Mas prova que, com efeitos especiais e artistas famosos, mesmo o velho ceticismo é capaz de dar dinheiro. 
A hipótese vai bem, embora possamos pensar em algumas conseqüências desconfortáveis para o sr. Skep. Afinal, se ele realmente pensa que pode ser um CNC, é porque deixou de se enganar e passou a enfrentar a dura realidade que a verdade da sua hipótese pode implicar. Ele poderá acreditar que o mundo real é o seu mundo possivel e daí, poderá concluir: "Não sou o cético sr. Skep nem estou num mundo em que há outras pessoas e coisas que podem ser objeto de minhas experiências. Eu estava errado. Sou apenas um CNC que pensava ser um cético. Não há outras pessoas, nem coisas fora de mim. Só há implantes de imagens e conceitos colocados em mim por um maligno supercomputador". Como o senhor Skep se leva a sério, ele corre o risco de afundar num limbo existencial.

Putnam é um filósofo realista. ${ }^{18}$ Seu problema é a possível verdade da hipótese do sr. Skep. Se o senhor Skep estiver certo, é o fato de podermos ser mais o fato de podermos saber que somos CNC, conjuntamente, que podem fazê-lo entrar em pânico. Essa conjunção de possiveis resulta da premissa de Skep, a saber, que não podemos saber o que, de fato, somos. Como filósofo realista que é, Putnam quer provar ao senhor Skep que tudo isto não passa de uma fantasia, que nem possivelmente somos $\mathrm{CNC}$.

O problema é encontrar a prova capaz de garantir que não podemos ser CNC. Putnam vai proceder exatamente como Kant: ele começa explorando os detalhes da própria hipótese de Skep: ao afirmar que é um CNC, Skep pressupõe que somente o que é interno é cognoscível, que ele não pode ter conhecimento de coisas externas, mas apenas de imagens, dados sensoriais, que são coisas que estão na sua mente. Skep, no entanto, não é um cético nihilista. Ninguém pode confrontar racionalmente um ceticismo nihilista ou anárquico. Se o ceticismo quer se apresentar como plausível, ele terá que partir de algum lugar. Skep é um cético localista (ver acima); pois há coisas que ele aceita e há coisas que ele não aceita. E entre aquelas que ele aceita, duas são decisivas: (a) temos experiências de coisas internas e (b) nossos pensamentos podem ser verdadeiros, desde que façam referência aos objetos destas experiências.

A hipótese localista de Skep tem um quê de empírica e logicamente defensável. Ainda assim, Putnam afirma que não pode haver um mundo no qual sejamos CNC. Ele afirma que "possível, verdadeira e realmente, não podemos ser cérebros

18 O realismo de Putnam, como ele diz, é interno. Mas não devemos confundir este tipo de internalis-
mo metafísico com as teorias semânticas que chamo de internalistas. Como é sabido, Putnam tam-
bém vê, no seu argumento, um modo de refutar a tese do realismo externo ou mágico, ou seja, a
tese de que a mente teria acesso imediato às coisas extemas, tais como elas são. Como metafísico
internalista, ele considera que a acessibilidade às coisas é sempre mediada por sistemas de crenças
e teorias. É nesta mediação que moldamos o mundo externo, de forma que o mundo tome-se co-
nhecido para nós. Isto é perspectivismo epistêmico (ou kantismo) mas não é internalismo epistêmi-
co. Como perspectivista e realista, Putnam não aceita que nossas teorias fazem o mundo exterior.
Esta seria uma forma de perpectivismo extremista. Putnam afirma que nossas teorias interagem
com o mundo externo e que, na interação, constitui-se o mundo que podemos conhecer. Em outra
ocasião, sustentei que a posição perspectivista cria problemas semânticos graves, para Putnam e
para todos aqueles que sustentam a identidade entre propriedades semânticas e propriedades epis-
temológicas. Ver Luis Milman, Atomismo versus Holismo, um estudo sobre a natureza das proprie-
dades semânticas, Tese de Doutorado, UFRGS, 1998 . 
numa cuba". O que explica essa impossibilidade, segundo ele, ${ }^{19}$ é que um CNC não pode dizer (ou pensar) que é um CNC, e pressupor que seus juízos/enunciados possuam a propriedade de ser, em dado momento, ou verdadeiros ou falsos. ${ }^{20}$ Para Putnam, a hipótese é ilícita porque destrói a si própria. Passemos à demonstração desta impossibilidade.

No mundo possível de Skep, quando tem a experiência de ser mordido por um cão, um CNC ignorante acerca da sua identidade, tem a sensação de ter sido mordido por algo que ele realmente acredita ser um cão. Se pedíssemos a um CNC na fase da inocência epistêmica para descrever o que havia acontecido a ele, ele provavelmente diria, "fui mordido por um cão" e não "fui mordido pela imagem de um cão" ou algo semelhante. Um CNC, ainda que inocente, pensa que sabe qual é a diferença entre uma coisa e a imagem desta coisa. $E$ pensa que sabe que é a mordida real de um cão real que torna o enunciado "fui mordido por um cão" verdadeiro (e não a mordida aparente de um cão aparente). Conclusão: no mundo possível de Skep, um ainda iludido CNC supõe que seus pensamentos e/ou proferimentos são verdadeiros ou falsos, e que é algo no mundo que os torna verdadeiros ou falsos. Isto vale para todos os pensamentos que podem ser instanciados por um CNC.

Se é este o caso, para que satisfaçam as condições que podem torná-los verdadeiros, é necessário que certas coisas ou estados de coisas, aos quaís pensamentos se referem, existam. Mas quais são as coisas ou estados de coisas que, por hipótese, tornam verdadeiro o enunciado "somos cérebros numa cuba", que um desiludido CNC, no mundo possivel de Skep, crê poder proferir, ao atingir a maturidade epistêmica?

Lembremos do pressuposto geral deste enunciado, que também é revelador do método da descoberta do Sr. Skep: se podemos pensar em qualquer coisa, mesmo que nada daquilo que pensamos corresponda a coisas exteriores, então podemos ser CNC. E a conclusão que a hipótese nos convida a extrair desta possibilidade é que, se somos CNC, então aquilo a que nos referimos com o enunciado "somos cérebros numa cuba" são a imagem de um ou mais cérebros e a imagem de uma cuba.

O ponto de partida da hipótese é, portanto, a negação do princípio segundo o qual nossos termos possuem referência externa. Nossas experiências seriam idênticas, mesmo que o mundo externo não passasse de mera aparência . Ouando

19 Nem mesmo uma solução kripkeana pode salvar a hipótese do senhor Skep. Kripke poderia dizer, prima facie, que há um mundo possivel que torna o enunciado "somos CNC" verdadeiro, a saber, um mundo no qual efetivamente somos CNC. Mas neste caso, Putnam, que admira a semântica dos mundos possiveis de Kripke, afirma explicitamente que este expediente é inaplicável, porque não há mundo possivel em que sejamos $\mathrm{CNC}$. Ver a demonstração a seguir.

Ou seja, suponham ser cogentes os princípios do terceiro excluído e da não-contradição. Dada a validade dos princípios para um CNC, ele pode mudar de opinião e admitir que pensava ser verdadeiro o que mais tarde ele descobriu ser falso. $O$ que ele não pode é dizer que qualquer enunciado é, ao mesmo tempo, verdadeiro e falso. Podemos substituir verdadeiro / falso por racionalmente asseverável/não-asseverável, justificável/não justificável, ou por qualquer outro par de antônimos epistêmicos, que isto não modifica em nada a tese de Putnam. 
pensássemos em cães, não estaríamos pensando em cães reais, mas em cães aparentes. A referência do pensamento "um cão está me perseguindo" seria a imagem de um cão associada à imagem de uma ação deste cão.

O sr. Skep nos autoriza a falar apenas de condições internas de satisfação para enunciados. Quais as condições intemas de satisfação do enunciado "estou diante de um cão" no mundo que Skep acredita ser possivel? Tais condições são dadas por um estímulo visual que produz em mim a imagem de um cão. Logo, se sou um $C N C$, eu jamais tive qualquer contato com cães reais, pois tais coisas não existem. O que torna a sentença "estou diante de um cão" verdadeira para um CNC iludido é a imagem de um cão.

A diferença entre aquilo que toma o enunciado verdadeiro para um CNC e o que torna o enunciado verdadeiro efetivamente é, neste ponto, toda a diferença que importa. Um CNC inocente, diante da imagem de um cão em sua mente, acredita que está diante de algo que pode mordê-lo no mundo extramental. Portanto, essa e todas as suas demais crenças são falsas, embora ele pense que essa e muitas outras (embora não todas) sejam verdadeiras. E com isso chegamos ao cerne do problema.

Por que não podemos dizer que somos $C N C$ ? Porque se somos CNC, então a sentença "somos CNC" é verdadeira se e somente se somos CNC. Mas repare: a hipótese permite apenas que "cuba" faça referência à imagem de uma cuba e não a uma cuba real. ${ }^{21}$, embora, pela mesma hipótese, somos cérebros numa cuba e não imagens de cérebros numa cuba. Segue-se que se o mundo possivel dos $C N C$ é o mundo real, e somos realmente cérebros numa cuba, então o que queremos dizer com "somos cérebros numa cuba" é que somos imagens de cérebros numa cuba. Mas se somos, pela hipótese, cérebros numa cuba, então, pela mesma hipótese, não somos imagens de cérebros numa cuba. E mais: a hipótese explicitamente apresenta o senhor Skep desiludido, que de fato acredita na possibilidade de seu enunciado ser verdadeiro (portanto, de não ser falso).

Assim, no mundo que Skep acredita ser possivel, se somos CNC, "somos CNC" é falso. ${ }^{22}$ Logo, não somos CNC, porque nenhum enunciado, segundo a própria pressuposição do senhor Skep, pode ser, ao mesmo tempo, verdadeiro e falso em qualquer mundo possivel. Pois no mundo possível em que é verdadeiro que somos CNC, "somos $C N C$ " é falso e somos imagens de $C N C$. Mas se somos imagens de CNC, então não somos CNC. A hipótese de que há um mundo possivel no qual somos CNC se autodestrói, porque a sua verdade, em qualquer mundo, implica a sua falsidade. A refutação da hipótese cética é transcendental: ninguém pode pensar ou dizer que é um $C N C$ sem pressupor que aquilo que pensa ou diz pode fazer referência a coisas externas. Ou seja, sem supor precisamente aquilo que pretende negar.

\footnotetext{
21 Putnam lembra que, também pela hipótese, os cérebros estão numa cuba real; e que portanto, há uma conexão extrínseca entre os cérebros e a cuba real, que torna possivel aos cérebros usarem a palavra cuba para se referirem à cuba real, na qual se encontram. Mas este fato dá conta de uma conexão entre estar numa cuba e o uso de qualquer palavra ou sentença. Não se trata, como ele adverte, de uma conexão especial que se obtém entre o uso da palavra 'cuba' e as cubas. Cf. Razon, Verdad e Histonia, p.27.
}

Op. cit. pp. 27-8. 


\section{Conclusão: o senhor Skep perde}

O senhor Skep perde, os internalistas perdem e, com eles, quaisquer hipóteses que sustentem que o significado é uma propriedade puramente funcional de um símbolo. Quem ganha é a velha metafísica das coisas que estão fora de nós, respaldada, por ora ao menos, nos princípios do Terceiro Excluído e da NãoContradição. Putnam está com Aristóteles e outros tantos realistas que, apesar de desacordos em outros pontos, aceitam que fora da bivalência não há pensamento possivel. O senhor Skep também acreditava na bivalência e partiu dela para imaginar um mundo possivel nos qual somos CNC. Por isso caiu em contradição. Só é possivel aquilo que, dependendo de uma série de contingências, é ou verdadeiro ou falso. E o enunciado "somos cérebros numa cuba", se é verdadeiro então é falso. Logo, é falso em todos os mundos possíveis. O senhor Skep não pode se insurgir contra a natureza da lógica subjacente ao seu próprio argumento.

Mas e se o senhor Skep insistisse? Se afirmasse que não há distinção entre enunciados verdadeiros e falsos? Se desafiasse o próprio caráter bivalente da lógica? Bem, neste caso, estariamos diante de um ceticismo diferente, que revoga pressupostos lógicos que parecem ser constitutivos das nossas práticas cognitivolingüísticas. Revoga, portanto, o ceticismo anterior do sr. Skep. Creio que, como perspectivista e relativista, Rorty estava pensando em algo deste tipo quando criticou os argumentos kantianos. Por isso, a primeira coisa a fazer seria perguntar ao senhor Skep o que ele efetivamente está tentando dizer com a sua nova hipótese. Desta vez, no entanto, chamaríamos a sua atenção para a condição que ele impõe a si mesmo: não dizer nada que acredite ser apenas verdadeiro ou apenas falso, porque ele vai estar preso a um mundo no qual não há dicções que sejam ou apenas verdadeiras ou apenas falsas (somente dicções que são verdadeiras e falsas ao mesmo tempo). Parece-me que se insistisse neste ponto, o senhor Skep perderia a disputa por nocaute no primeiro minuto do primeiro round: ou seja, perderia não mais por redução ao absurdo, mas por esquizofrenia.

$\mathrm{O}$ argumento de Putnam impõe uma condição realista extrínseca e inerente à semântica. "Extrínseco" tem, aqui, um sentido metafísico-transcendental. Putnam admite, como realista e perspectivista, que uma teoria sobre a correspondência entre o que pensamos ou descrevemos e os fatos pensados ou descritos é uma questão aberta em epistemologia. Mas seu argumento não é epistemológico. É metafísico no que concerne à natureza relacional extrinseca das propriedades semânticas. E prova que mesmo perspectivistas como o próprio Putnam, devem aceitar que o conteúdo daquilo que pensamos e dizemos depende das coisas às quais nosso pensamento e linguagem fazem referência.

Quando o senhor Skep afirma que nós podemos ser CNC - alegando que não podemos provar que o pensamento, como dizem os filósofos da mente, é intencional, que é dirigido para coisas fora de nós, ele sustenta uma posição paradoxal: ao pretender que seu enunciado seja verdadeiro, ele é obrigado a pressupor que há algo que torna o seu enunciado verdadeiro. A afirmação de Skep supõe que os CNC possuam a capacidade/disposição/habilidade que nós temos de falar e de 
pensar referencialmente. No entanto, falar e pensar referencialmente como nós é justamente aquilo o argumento de Putnam prova ser impossível para os CNC. Logo, não podemos ser CNC.

Finalizando: Aceitar $\odot$ argumento de Putnam para a referência não implica concordar com o seu realismo perspectivista, da mesma forma que a aceitação dos argumentos da Refutação do Idealismo e da $2^{\mathrm{a}}$ Analogia não nos obriga a aceitar a doutrina transcendental da consciência. Mas esta é outra história. Importa, aqui, reconhecer, com Putnam, que a concepção da verdade como correspondência para a qual e, para dizer o mínimo, concordo que não dispomos de uma teoria adequada - é uma pressuposição, uma condição de possibilidade inerente tanto ao nosso pensamento como ao pensamento do senhor Skep.

\section{Referências bibliográficas}

Bird, Graham. "Kant's Transcendental Arguments", In: E. Chaper and W. Vossenkhul (orgs) (org) Reading Kant, Oxford, Blackwell, 1989.

Bubner, Rüdiger. "Kant Transcendental Arguments and the Problem of Deduction", In: Review of Metaphysics, 28, 1928

Dell'Utri, Massimo. "Choosing conceptions of realism: the case of the brains in a vat". Mind, XCIX.

Descartes, René. Meditationes de Prima Philosophia, (trad. ing. De J. Cottingham, R. Stoothoff \& D. Murdoch, In: The Philosophical Writings of Descartes, Cambridge, Cambridge University Press, 1985).

Field, Hartry. "Logic, Meaning and Conceptual Role", In: The Joumal of Philosophy, LXXIV, 1977. pp. 379-409.Förster, Eckart.

"How Are Transcendental Arguments Possible", In: E. Chaper and W. Vossenkhul (orgs) (org) Reading Kant, Oxford, Blackwell, 1989.

Hume, David. Essays Conceming the Human Understanding (trad. port. Investigação sobre Entendimento Humano, Lisboa, Edições 70, 1989.

Kant, Immanuel. Kritik der Reinen Vemunft, $2^{a}$ ed., 1787 (trad. port. Crítica da Razão Pura, Lisboa, Fundação Calouste Gulbekian, 1989).

Kömer, Stephen. Categonial Frameworks, Oxford, Basil Blackwell, 1974.

Kripke, Saul.Naming and Necessity, Oxford, Basil Blackwell, 1980.

Putnam, Hilary. Mathematics, Matter and Method. Philosphical Papers, vol.1, Cambridge, Cambridge University Press, 1975.

Press, 1975 .

_. Meaning and the Moral Sciences, London, Routledge \& Kegan Paul, 1978.

- Reason, Truth and History, Cambridge, Cambridge University Press, 1981 (trad. esp. Razon, Verdad e Historia, Madrid, Tecnos, 1988). 1983.

, Representation and Reality, Cambridge, The MIT Press, 1990.

Rorty, Richard. "Transcendental Arguments, self-reference and pragmatism", In: R. P. Bieri et alii (eds), Transcendental Arguments and Science, Dordrecht, Riedel Publishing Co., 1979. 